\title{
Investigation on Seismic Damage Model Test of a High Concrete Gravity Dam Based on Application of FBG Strain Sensor
}

\author{
Mingming Wang $\mathbb{D},{ }^{1}$ Jianyun Chen $\left(\mathbb{D},{ }^{2}\right.$ Hai Wei $\left(\mathbb{D},{ }^{1}\right.$ Bingyue Song, ${ }^{1}$ and Weirong Xiao ${ }^{1}$ \\ ${ }^{1}$ Faculty of Electric Power Engineering, Kunming University of Science and Technology, Kunming 650500, China \\ ${ }^{2}$ State Key Laboratory of Coastal and Offshore Engineering, Dalian University of Technology, Dalian 116024, China \\ Correspondence should be addressed to Hai Wei; weihai2005@126.com
}

Received 1 February 2019; Accepted 28 May 2019; Published 1 July 2019

Academic Editor: Xiaopeng Zhao

Copyright (c) 2019 Mingming Wang et al. This is an open access article distributed under the Creative Commons Attribution License, which permits unrestricted use, distribution, and reproduction in any medium, provided the original work is properly cited.

\begin{abstract}
A 203-m-high gravity dam being built in earthquake-prone areas needs to be investigated very carefully to determine its dynamic responses, damage mechanism, and safety evaluation. The dynamic characteristics, seismic responses, failure mode, and safety evaluation of the above structure are presented through dynamic fracture test for small-scale model on shaking table. Because the strength of the model material is very low, the traditional strain gauge is also not easy to be glued to the surface of model. It is difficult to measure the accurate strain data of small-scale model during testing. Therefore, Fiber Bragg Grating (FBG) strain sensor is presented to obtain the strain of small-scale model during testing, due to its high sensitivity. The dynamic strain and residual strain are obtained with the FBG sensors embedded in model. The FBG sensor is adhered to model material completely and shows advantages of ease for installation, high sensitivity, and reliability compared with traditional resistance strain gauge. The model during testing is submitted with earthquake wave from the Chinese Code. In the experiment, the peak ground acceleration (PGA) of the first crack in the model indicates the safety level of the gravity dam. The crack locations and forms determine the damageable part of gravity dam under intense earthquake. After the final analysis, the safety evaluation result of the gravity dam under strong earthquake is given in order to guide the implementation of the project.
\end{abstract}

\section{Introduction}

China is the country with the largest population; the largest number of consumers leads to a great demand for energy. So far many hydropower stations have been built to provide a large amount of electricity. Meanwhile we know that dam concrete is a low tension material, and concrete gravity dam is easy to cause cracks in earthquake. The cracks in the gravity dam usually extend from microcracks to penetrating cracks. Therefore, studying the damage behaviors of concrete dam is indispensable if it comes to monitoring the safety and stability of dam.

With rapid developments of computer and Finite Element Method (FEM), in recent decades, a large number of scholars adopted the computer and FEM to research dynamic characteristics of concrete dam in earthquake [1-9]. However, different scholars use different finite element models, material constitutions, boundary conditions, load inputting, and simplification in dynamic analyses for the concrete dams; their results are quite different. Hence, dynamic model test is a useful supplement and validation of numerical method. A large number of model tests to investigate the seismic damage characteristics of concrete dam have been held over several decades [10-21].

The traditional strain gauge was adopted to measure the strain in previous model experiment. The strain gauge was bonded to the surface of experimental model with cyanoacrylate, RTP-801, or acrylate glue. However, the glues are unsuitable for bonding strain gauge to model surface. None of the glues are suitable for attaching strain gauge to the surface of model, because the glues' strengths are greater than that of the model material in model test. In addition, in the process of small-scale concrete dam model produced by model material, the curing period of the model is short, only 24-48 hours, which leads to the model surface to be moist during testing. This case reduces the resistance of strain gauge and leads to the strain measurement being seriously affected because of the wettability. Moreover, the strain gauge 


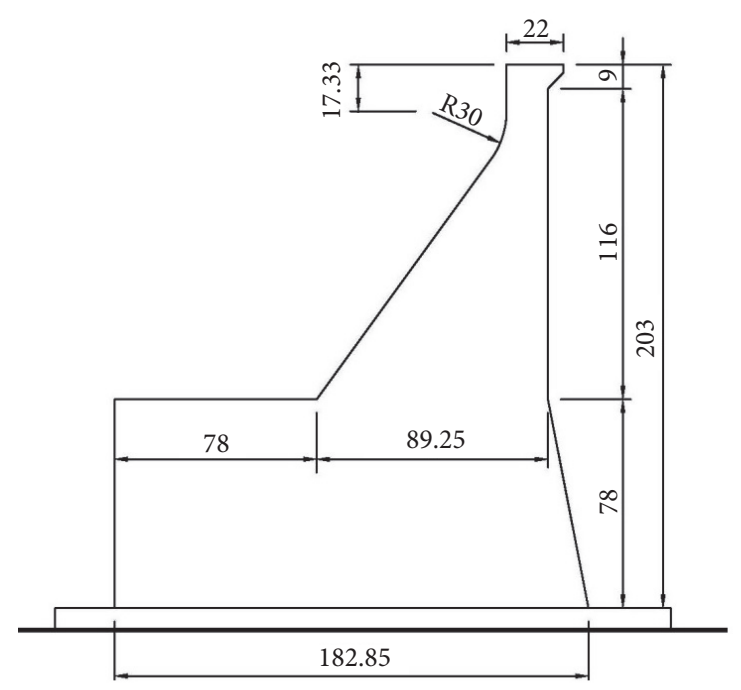

FIGURE 1: Scaled model dam of the concrete gravity dam (unit: m).

attached to the damp surface of model may fall off during vibration of model. Besides the glue for bonding strain gauge may react chemically with the model material influencing the accuracy of measured data. Based on the above, the strain measured by traditional resistance strain gauge during the model testing cannot satisfy the above special requirements. Kinds of sensors with sensitivity, easy to install, and with exactitude, such as differential current sensor, have been used to measure the model strain during testing [22]. But the external deformation of model cannot generally reflect the failure condition in the model. Accurate measurement of strain variation and effective prediction of internal damage of model are the main objectives of strain sensors during dynamic failure model testing. Fiber Bragg Grating (FBG) is a kind of diffraction grating whose refractive index changes periodically. It has attracted wide attention in optical sensing technology because of its flexibility, embeddedness, multidispersion, high sensitivity, and antielectromagnetic interference immunity $[23,24]$. It can also be embedded in structure to detect more detailed damage information. In more recent years, engineering scholars have applied the FBG strain sensor in concrete structure to measure internal strain [25-27].

In order to avoid the failure of exposed FBG sensor in concrete, many design concepts of protection systems for embedded FBG sensors in concrete structure have been proposed by previous researchers $[25,29,30]$. The FBG sensor wrapped in metal tube is widely adopted since metal material can be bonded well to concrete. A large number of scholars have researched the strain transfer mechanism and sensing performances of the packaged FBG sensor [31-33].

The previous studies were on the basis of the mechanical test of normal concrete that the elasticity modulus is more than $2 \times 10^{4} \mathrm{MPa}$. However, in the case of low elasticity modulus of model material for small-scale model test, the cohesive force between the metal pipe and model material cannot deform the metal pipe sufficiently because the metal elasticity modulus is 1000 times more than the modulus of model material. The deformation transfer loss is an important factor affecting the sensitivity of FBG strain sensor. It is unavoidable and exists between model material and packaging material.

A 203-m-high concrete gravity dam is being built in earthquake-prone areas. The dynamic characteristics, seismic responses, failure mode, and safety evaluation for overflow section of the above dam have been studied in detail by the authors [28].

In the paper, the whole step of the dynamic failure model test for the water retaining section of the gravity dam is presented to investigate its dynamic responses, failure mechanism, seismic performance, and safety. The seismic input wave is the Chinese Code earthquake wave. Firstly, a type of FBG strain sensor is developed and used in the dynamic small-scale model test. To investigate the applicability of the FBG strain sensors in the tests, the dam model is tested on the shaking table. Secondly, the model design, measurement layout, and test procedures are described. Finally, the dynamic failure model dam test and the analysis of the test results are presented for water retaining section of the high gravity dam.

\section{Description of Dam Structure}

The authors have published a research article which presents a study on the dynamic characteristics for overflow section of a 203-m-high gravity dam [28]. The project about the above dam has been described in detail in [28].

The water retaining section of the water conservancy and hydroelectric project mentioned in [28] is studied in this paper.

For investigating the dynamic response, seismic performance, and damage form of the gravity dam, the 10 \# water retaining section which is the highest section of the gravity dam is subjected to a dynamic failure model test on shaking table. The section of the gravity dam is designed as shown in Figure 1. 
TABLE 1: Similar ratios for the model test [28].

\begin{tabular}{|c|c|c|c|c|}
\hline Parameter & Relationship & Model/Prototype & Prototype value & Model target value \\
\hline Length & $S_{l}$ & $1 / 100$ & - - & - - \\
\hline Density & $S_{\rho}$ & $1.2245 / 1$ & $2450 \mathrm{Kg} / \mathrm{m}^{3}$ & $3000 \mathrm{Kg} / \mathrm{m}^{3}$ \\
\hline Dynamic Young's modulus & $S_{E}=S_{l} \cdot S_{\rho}$ & $1 / 81.667$ & $33.15 \mathrm{GPa}$ & $0.4059 \mathrm{GPa}$ \\
\hline Time & $S_{t}=\sqrt{S_{l}}$ & $1 / 10$ & - - & - \\
\hline Acceleration & $S_{a}=1$ & $1 / 1$ & - - & - - \\
\hline Stress & $S_{S}=S_{l} \cdot S_{\rho}$ & $1 / 81.667$ & - - & - - \\
\hline Tensile strength & $S=S_{1} \cdot S$ & $1 / 81667$ & $2.34 \mathrm{MPa}$ & $28.653 \mathrm{KPa}$ \\
\hline Compression strength & $\mathrm{u}_{\sigma}-\mathrm{s}_{l} \cdot \mathrm{s}_{\rho}$ & & $24.57 \mathrm{MPa}$ & $0.3009 \mathrm{MPa}$ \\
\hline Strain & $S_{\varepsilon}=1$ & $1 / 1$ & - - & -- \\
\hline
\end{tabular}

TABLE 2: Quality mixture ratio for the fine aggregate model material [28].

\begin{tabular}{lcccc}
\hline Cement & Water & Admixture & Sand & Fine aggregate \\
\hline $1.5 \%$ & $8.5 \%$ & $10.0 \%$ & $34.0 \%$ & $46.0 \%$ \\
\hline
\end{tabular}

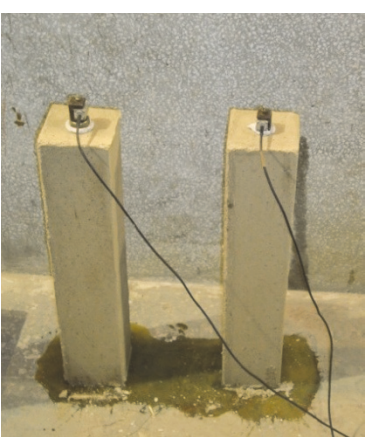

(a) Percussion cantilever test

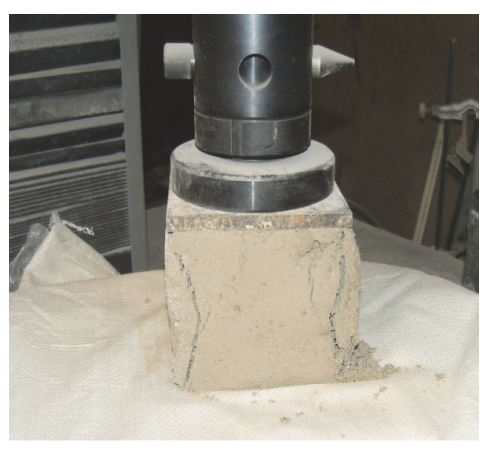

(b) Uniaxial compressive test

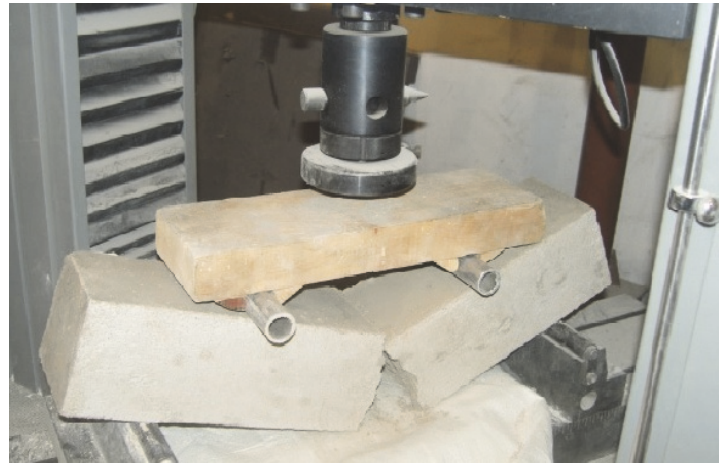

(c) Four-point bending beam test

FIgURE 2: Model material tests for mechanical proportions [28].

\section{Similitude Rules and Dam Model Materials}

3.1. Similar Scale Requirement for Test. Because of the size and bearing capacity of the shaking table, the dam model is reduced according to a similar scale based on the size and material property of prototype dam.

The basic principle of similar scale has been described in detail in [28]. Because the prototype and model dams are in the same gravity field, the well-known 3 fundamental similitude laws are expressed by following equations:

$$
\begin{aligned}
& \lambda_{t}=\sqrt{\lambda_{l}} \\
& \lambda_{S}=\lambda_{\rho} \lambda_{l} \\
& \lambda_{a}=1
\end{aligned}
$$

where $\lambda_{t}, \lambda_{l}, \lambda_{S}, \lambda_{\rho}$, and $\lambda_{a}$ stand for the similar scales of time, geometric size, stress, density, and acceleration, respectively.

For the bearing capacity and size of shaking table in Structural Engineering Laboratory at Kunming University of Science and Technology in China, the geometric scale $\lambda_{l}$ between the prototype and model is determined to be 100 : 1 for the test. Similar scales of other parameters $\left(\lambda_{t}, \lambda_{S}, \lambda_{\rho}\right.$, and $\lambda_{a}$ ) are given by (1), (2), and (3). For all similar scales, the physical and mechanics parameters of model material for the test are shown in Table 1.

3.2. Simulation Model Material. To the small-scale model failure test under earthquake, the Simulation Model Material (SMM) is proposed in [28]. The aggregate in prototype concrete is simulated by fine aggregate. The mass mix ratio of SMM is shown in Table 2 based on similar scales in Table 1.

The material tests for the mechanical parameters of SMM are shown in Figure 2, which is the same as in [28]. The dynamic elastic modulus of SMM is about $400 \mathrm{MPa}$ from the percussion cantilever test. The compression strength of SMM is about $0.3 \mathrm{MPa}$ from the uniaxial compressive test, and the tension strength of SMM is about $0.028 \mathrm{MPa}$ from four-point bending beam test. The density of SMM is about $3000 \mathrm{Kg} / \mathrm{m}^{3}$. The dam model weighs about 3 tons. 


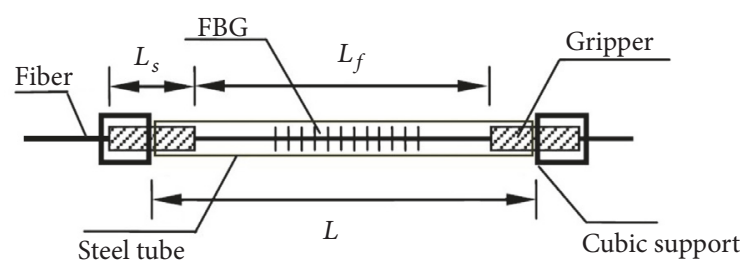

FIGURE 3: Diagrammatic sketch of the packaged FBG sensor.

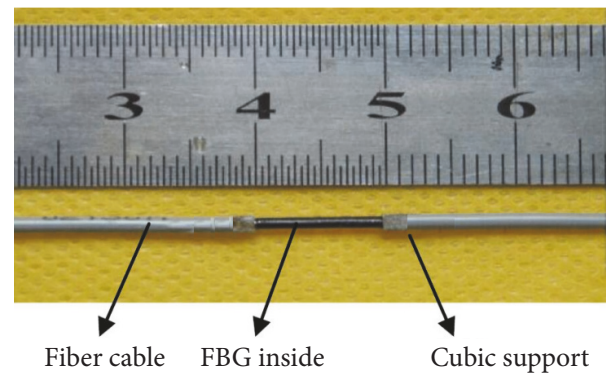

FIGURE 4: Photo of the packaged FBG sensor.

\section{FBG Strain Sensor Design}

Fiber Bragg Grating strain sensor packaged in a metal tube or capillary is now in widespread use. However, the cohesive force of SMM to metal tube cannot make the metal tube deform adequately because of the low strength of the model material. The deformation transfer loss is an important factor affecting the sensitivity of FBG strain sensor. It is unavoidable and exists between the model material and packaging tube. To a certain extent, it puts forward new requirements for improving FBG sensor sensitivity. According to the basic principles of friction pile and end bearing pile diffusely applied for civil engineering field, a cubic shape fixing support is designed to improve the surface roughness of FBG strain sensor and cohesive force between the senor and the model material. A gripper fixed on the cubic support is arranged on each side of FBG strain senor to transfer the cohesion to the strain sensor. The fibers on each side of the strain sensor are packaged in neoprene adhesive with a gripper on each side of the strain sensor. The gripper is mounted on the cubic support by soldering tin. The exposed FBG strain sensor between the two grippers is packaged in the metal pipe. During concrete-like material pouring, the metal pipe plays a role in protecting FBG sensor from external stress and pressure and also does not transfer material deformation to FBG strain sensor. The cubic support and gripper can slither freely along the metal pipe. The cohesion between the support and the model material makes gripper slither through metal pipe and gives rise to the deformation of FBG strain sensor which is, namely, the strain measured. The diagrammatic sketch of small size FBG sensor is shown in Figure 3, and the photo of the sensor is shown in Figure 4.

FBG of the sensor proposed in this study is not in direct contact with the neoprene adhesive. Therefore, the sensor not only greatly reduces the strain transfer loss, but also eliminates the multipeak phenomenon of FBG reflected light caused by the uneven distribution of the neoprene adhesive.

A previous study [34, 35] has shown that the stress transfer loss between the fiber and neoprene adhesive can be neglected when the adhesive thickness is less than the diameter of the fiber, and the relative deformation of the grippers at both ends of FBG is also the deformation of FBG, which are given as

$$
\begin{gathered}
\Delta L_{S}=\frac{P_{s} L_{s}}{E_{s} A_{s}} \\
\Delta L_{f}=\frac{P_{f} L_{f}}{E_{f} A_{f}}
\end{gathered}
$$

where $L, L_{s}$, and $L_{f}$ are the distance between the two cubic supports and the gripper and FBG lengths, respectively; $E_{s}$, $E_{f}, A_{s}$, and $A_{f}$ are the elasticity modulus and section areas of metal tube and fiber, respectively; $P_{s}$ and $P_{f}$ are, respectively, the tensile forces in gripper tubes and FBG. Because the tensile forces $\left(P_{s}=P_{f}\right)$ are constant throughout the FBG strain sensor, the strain ratio between the gripper tube and FBG is given as [34]

$$
\frac{\varepsilon_{s}}{\varepsilon_{f}}=\frac{\Delta L_{s} / L_{s}}{\Delta L_{f} / L_{f}}=\frac{E_{f} A_{f}}{E_{s} A_{s}}
$$

The mechanical properties of the FBG sensor are shown in Table 3. Substituting the parameters in Table 3 into (6), the strain ratio is obtained $\left(\varepsilon_{s} / \varepsilon_{f}=0.0084\right)$. Therefore, the relative deformation between the two cubic supports is given as [34]

$$
\begin{aligned}
\varepsilon & =\frac{\Delta L_{f}+\Delta L_{s}}{L}=\frac{L_{f} \varepsilon_{f}+L_{s} \varepsilon_{s}}{L}=\frac{L_{f} \varepsilon_{f}+0.0084 L_{s} \varepsilon_{f}}{L} \\
& =\frac{L_{f}}{L} \varepsilon_{f}\left(1+0.0048 \frac{L_{s}}{L_{f}}\right)
\end{aligned}
$$

The relative deformation between the two supports is the same as the deformation of FBG between the two grippers for $L_{s} / L_{f}<1$ and $0.0084 L_{s} / L_{f}=1$. The relational expression between the displacement $\Delta \lambda$ of FBG central wavelength and the strain $\varepsilon$ of FBG sensor is given as [36]

$$
\begin{aligned}
\varepsilon_{f} & =\frac{L_{f} \Delta \lambda_{F B G}}{1.2 L} \\
\varepsilon & \approx \frac{L_{f}}{L} \varepsilon_{f}=\frac{L_{f} \Delta \lambda_{F B G}}{1.2 L}
\end{aligned}
$$

The central wavelength of FBG is $1550 \mathrm{~nm}$. Based on (8), the FBG strain sensor sensitivity is decided by $L / L_{f}$ and can be amplified by adjusting the mechanical structure because of $L>L_{f}$. 
TABLE 3: Mechanical properties of FBG [34].

Component Elasticity modulus/MPa Diameter/mm

Fiber core/ $E_{f}$ $72 \times 10^{9}$ 0.125

Gripper tube/ $E_{s}$

$210 \times 10^{9}$

0.800

TABLE 4: Shaking table technical parameters.

\begin{tabular}{lc}
\hline Indexes & Parameters \\
\hline control mode & $\begin{array}{c}\text { Digital control } \\
\text { drive mode }\end{array}$ \\
Vibrating direction & Horizontal and vertical \\
Loading capacity & $20 \mathrm{t}$ \\
working area size & $4 \times 4 \mathrm{~m}$ \\
Max. horizontal displacement & $\pm 75 \mathrm{~mm}$ \\
Max. horizontal velocity & $\pm 50 \mathrm{~cm} / \mathrm{s}$ \\
Max. horizontal acceleration & $1.0 \mathrm{~g}$ \\
Max. horizontal displacement & $\pm 50 \mathrm{~mm}$ \\
Max. horizontal velocity & $\pm 35 \mathrm{~cm} / \mathrm{s}$ \\
Max. horizontal acceleration & $0.7 \mathrm{~g}$ \\
Vibrating frequency ranges & $0.1-100 \mathrm{~Hz}$ \\
Max. height of gravity center & $1.0 \mathrm{~m}$ \\
Max. height of eccentricity center & $0.5 \mathrm{~m}$ \\
\hline
\end{tabular}

\section{Dam Model Experiment}

5.1. Test Equipment, Model Production, and Instrumentation. The dynamic failure model test has been widely applied to study dynamic characteristics of dam structures in earthquake. The seismic failure model test for the above $203 \mathrm{~m}$ high gravity dam is carried out on the shaking table in Structural Engineering Laboratory at Kunming University of Science and Technology in China. The technical parameters of the shaking table used in the test are shown in Table 4.

The geometric scale $\lambda_{l}$ between the prototype and model is determined to be 100: 1 for the test. From the loading capacity of shaking table and dam section in Figure 1, the dam model is designed to satisfy the $1 / 100$ of the geometrical dimensions of the prototype dam. Figures 5, 6, and 7 show, respectively, the installation of model, the pouring of model, and the outside view drawing of model after the manufacture. The model is solidly bolted to the shaking table to ensure a transmission effect of the inputting seismic wave from the platform to the model bottom, as shown in Figure 7.

For simulating the impact of reservoir water on the dam during earthquake, seven lead blocks of a certain mass are embedded on the upstream of dam model, as additional mass. According to Westergaard's Additional Mass Method, the mass and location of the additional lead blocks are determined under earthquake in which the PGA is $0.251 \mathrm{~g}$, as shown in Figure 8. When pouring the model, the small lead blocks of determined quality are fixed in the designated positions inside the formwork of the upstream surface of the model with fine wire. When removing the formwork, the lead blocks can be firmly fixed in the designated positions in the upstream surface of the model by cutting the wire.

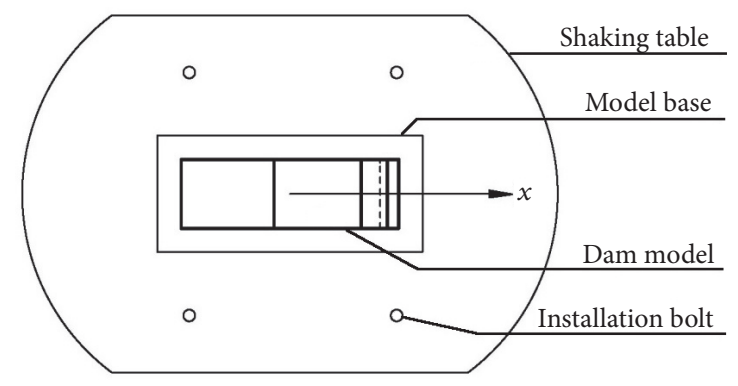

FIGURE 5: Model installation.

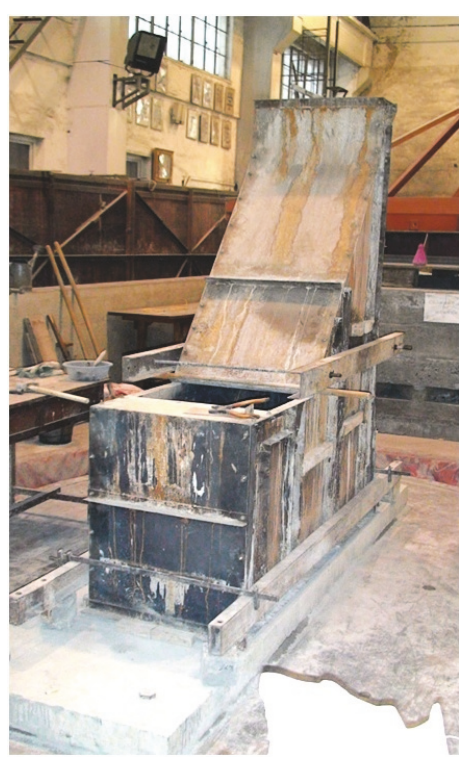

FIGURE 6: Model construction process.

Because of gravity these additional masses compress or stretch the upstream face and provide a tendency to close or open cracks in the dam model. Because the cracks appear at the nape of dam where the water depth is shallow, the additional mass is too small to have a significant impact on the above.

The accelerometers and FBG sensors are used to measure the accelerations and strains of different positions of the model during testing. The displacements can be obtained by the quadratic integral of the accelerations.

The arrangements of accelerometers are shown in Table 5 and Figure 8, and 6 accelerometers are used for the model test. Among them, 4 (AC1-AC4) are used to measure the horizontal accelerations, and 2 (AC5 and AC6) are used to obtain the vertical accelerations. As for FBG sensors, a total 
TABLE 5: Accelerometers arrangements of model test.

\begin{tabular}{lcr}
\hline Accelerometer & Direction & Location \\
\hline AC1/AC6 & Along stream horizontal/Vertical direction & At the base \\
AC2 & Along stream horizontal direction & $105 \mathrm{~cm}$ of the base \\
AC3 & Along stream horizontal direction & $150 \mathrm{~cm}$ of the base \\
AC4/AC5 & Along stream horizontal/Vertical direction & At the crest \\
\hline
\end{tabular}

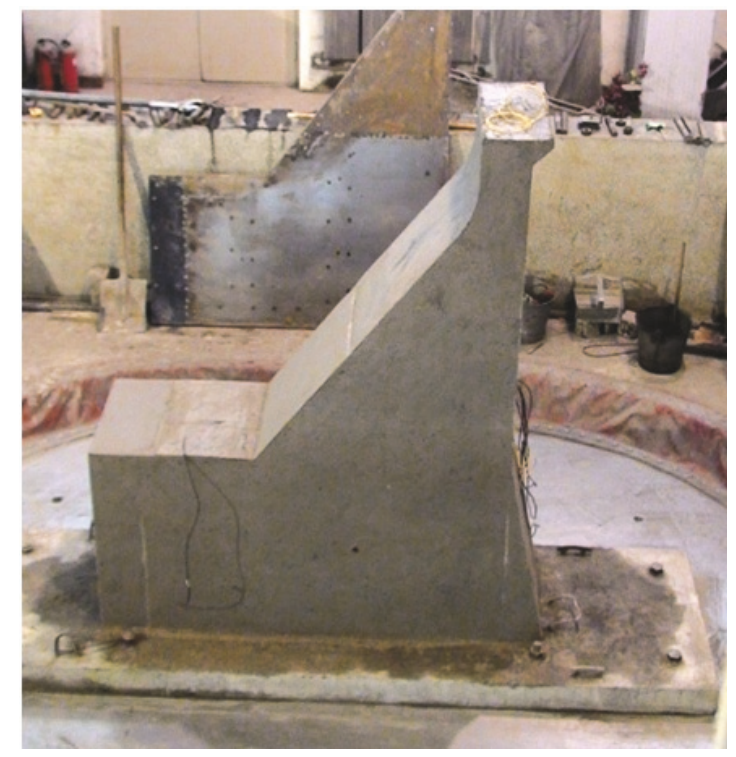

FIGURE 7: Overview of the model dam.

10 are used for the model test. The mounting positions of FBG sensors are presented in Figure 8. In order to collect data, a computer controlled Data Signal Process System (DSPS) is adopted during testing, as shown in Figure 9.

5.2. Test Program. The earthquake wave which is an artificial wave generated from response spectrum for seismic Code in China is adopted for the model test, as shown in Figure 10. The Chinese Code response spectrum is drawn in Figure 11.

In order to check the integrity of the model, the response of model is obtained by using white noise excitation of $0.05 \mathrm{~g}$ at the beginning of the model test. The model foundational frequency can be obtained by calculating the transfer function of white noise excitation, too. Then, the increasing earthquake excitations step by step are inputted for the dynamic model failure test. The gradually increasing loading method is the equal of earthquake duration increased. It causes damage of model in a lesser degree before the first crack appears. In this case, obtaining PGA which produces the first crack at the model during testing is a bit smaller than it really is. So the results from this loading method will give safe conclusion for assessing the safety of gravity dam subjected to intense earthquake.

According to similar scale ratios in Table 1 that the time scale between the prototype and model is 10:1, the frequencies scale is 1:10. A series of seismic wave inputs is adopted during testing, as listed in Table 6. The shaking table is adopted to

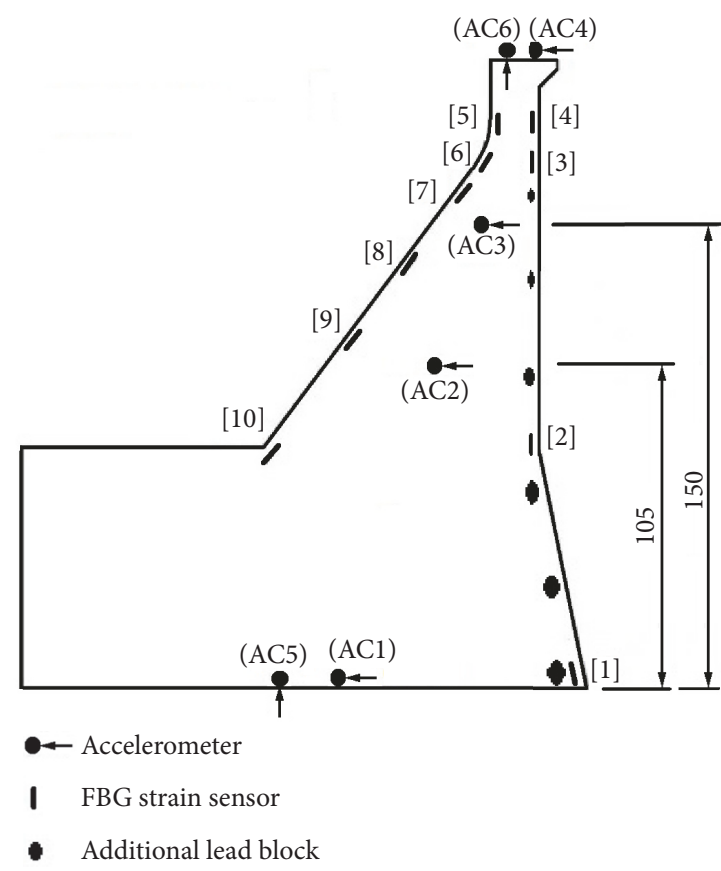

FIGURE 8: Arrangement of strain gauges for the model.

input the seismic wave to the model at horizontal stream and vertical directions. The PGA of the vertical/horizontal directions is $2 / 3$.

\section{Experimental Results and Analysis}

6.1. Frequencies Analysis of Model. The white noise of $0.05 \mathrm{~g}$ is applied during testing to get the dam model foundational frequency. The natural frequency is $25.65 \mathrm{~Hz}$ for the model that is inputted by the white noise of $0.0614 \mathrm{~g}$.

During the testing, the foundational frequencies of the model are shown in Figure 12. The foundational frequencies changes are very small during the Load Cases SW1-SW4. That is to say, there is not obvious damage to the model under the earthquake input of $0.3458 \mathrm{~g}$. The natural frequency of the model is obviously reduced under the Load Case SW5 and behind. This means that the model has been significantly damaged under earthquake with PGA of more than $0.3458 \mathrm{~g}$. Although the naked eye cannot be seen at this time, the model has been cracked firstly. After the earthquake with PGA of $0.4826 \mathrm{~g}$ inputs for the testing, the natural frequency of the model is declined rapidly. At the end of testing, the foundational frequency dropped considerably as the model is completely damaged and $7.00 \mathrm{~Hz}$ for model. 
TABLE 6: A series of seismic inputs.

\begin{tabular}{lcc}
\hline Load Case & Target PGA & PGA on platform (Recorded AC1) \\
\hline WN & $0.05 \mathrm{~g}$ & 0.0614 \\
SW1 & $0.15 \mathrm{~g}$ & 0.1533 \\
SW2 & $0.20 \mathrm{~g}$ & 0.2258 \\
SW3 & $0.25 \mathrm{~g}$ & 0.2741 \\
SW4 & $0.30 \mathrm{~g}$ & 0.3458 \\
SW5 & $0.40 \mathrm{~g}$ & 0.4826 \\
SW6 & $0.60 \mathrm{~g}$ & 0.8961 \\
SW7 & $1.0 \mathrm{~g}$ & 1.2775 \\
SW8 & $1.40 \mathrm{~g}$ & 1.4176 \\
\hline
\end{tabular}

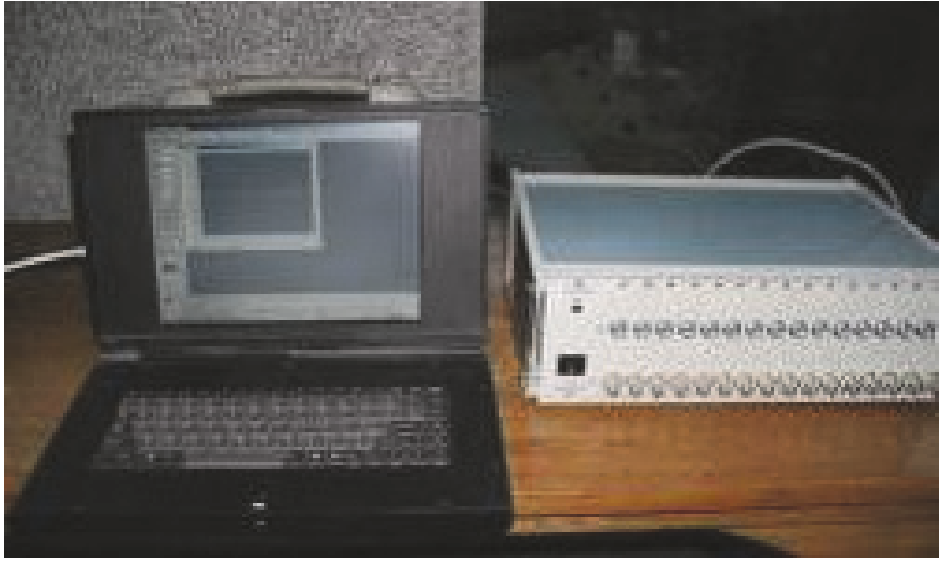

(a) DSPS system of data acquisition and processing

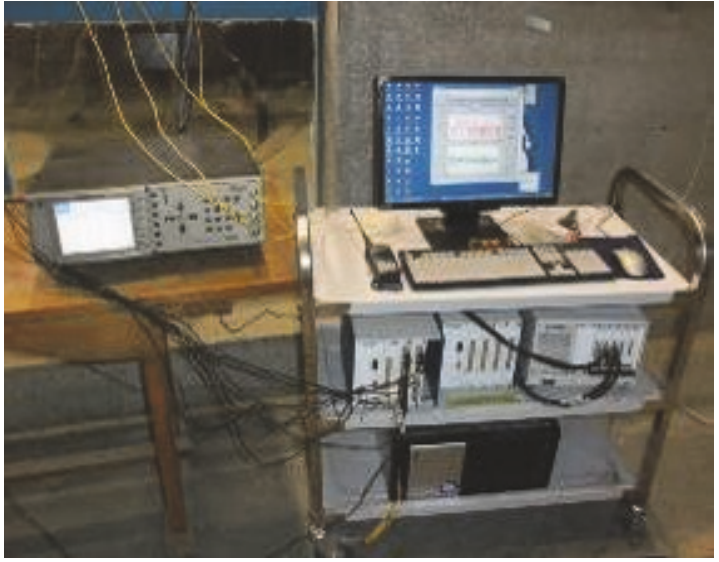

(b) FGB strain data collecting instrument

FIGURE 9: Data acquisition system.

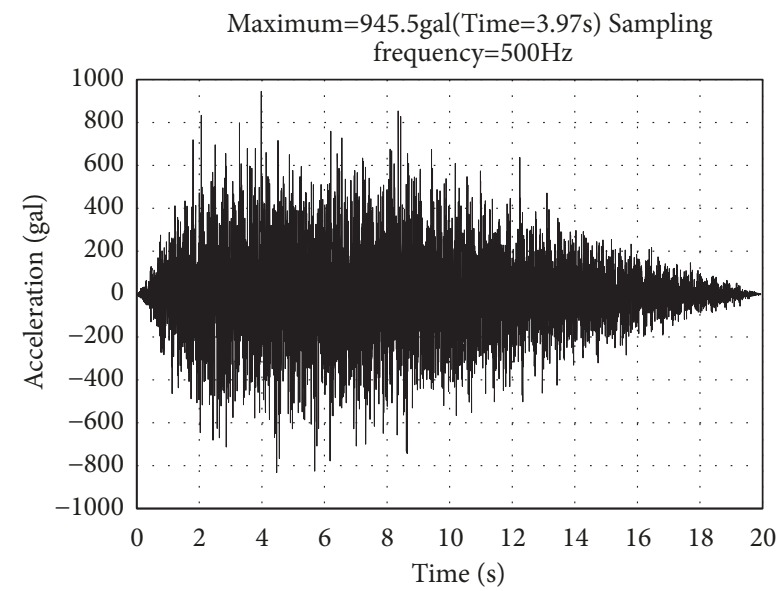

FIgURE 10: Inputting Chinese Code seismic wave.

6.2. Acceleration Responses of Model. The accelerations along height from the base to the crest for elasticity dam are amplified in earthquake. In this testing, the value of each accelerometer recorded on the model is presented in Table 7. According to Table 7, the acceleration multiplying factors along the model height under each load case are shown in Figure 13.

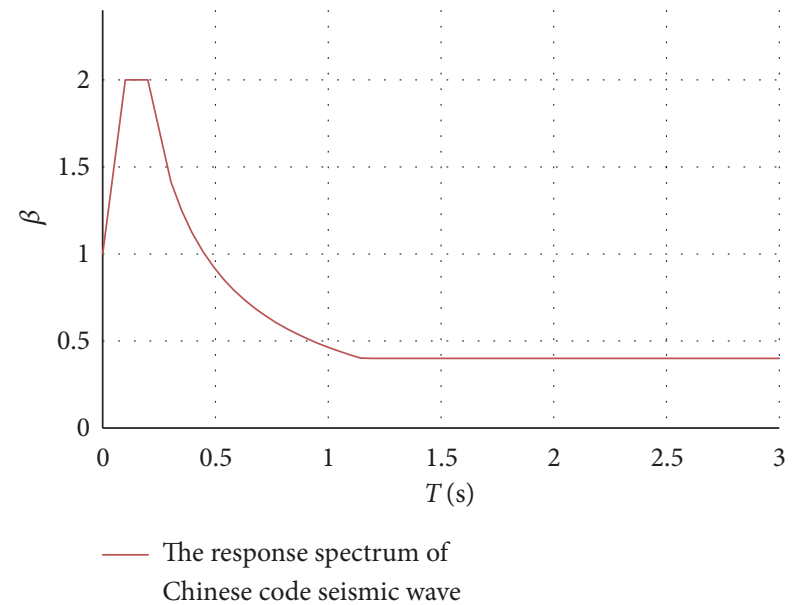

FIgURE 11: Response spectrum of Chinese Code seismic wave.

As shown in Figure 13, under the seismic wave inputs of the Load Cases SW1-SW4, the acceleration multiplying factors increase linearly along the model height and decrease with the seismic excitation intensity.

When the PGA inputs in the test reached $0.4826 \mathrm{~g}$, the accelerations at crest (AC4) of the model are less than those at 
TABLE 7: Maximum accelerations on the model. AC: Accelerometers; WN: White noise; SW: Seismic wave.

\begin{tabular}{lcccc}
\hline Load Case & AC1 & AC2 & AC3 & AC4 \\
\hline WN & 0.0614 & 0.1845 & 0.2560 & 0.7587 \\
SW1 & 0.1533 & 0.5150 & 0.9750 & 1.4354 \\
SW2 & 0.2258 & 0.7098 & 1.1844 & 1.8256 \\
SW3 & 0.2741 & 0.8073 & 1.3614 & 2.0010 \\
SW4 & 0.3418 & 0.8868 & 1.5294 & 1.1117 \\
SW5 & 0.4826 & 1.0994 & 1.9051 & 1.2986 \\
SW6 & 0.8961 & 1.7435 & 1.4380 & 2.0592 \\
SW7 & 1.2775 & 2.1258 & 1.9586 & 1.7199 \\
SW8 & 1.4176 & 1.9358 & & \\
\hline
\end{tabular}

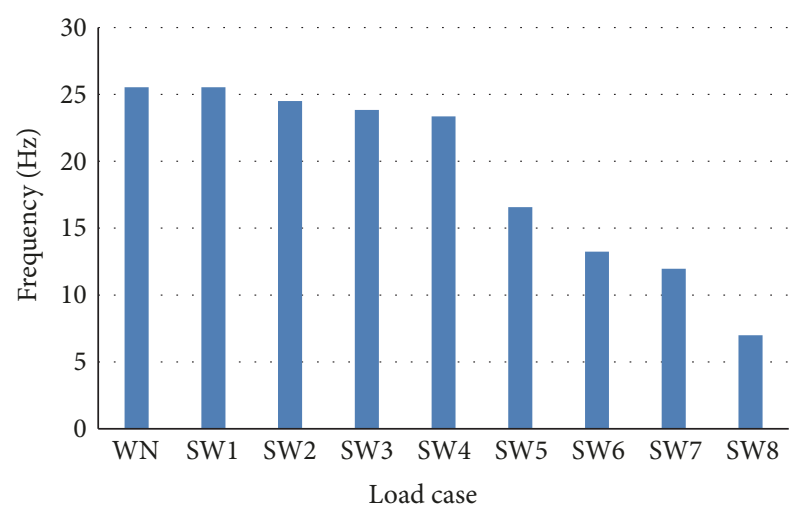

FIGURE 12: Variation of the foundational frequencies of the model.

neck (AC3) of the model. This indicates that crack occurs at the neck (positions above AC3) of the model and the model is stepped into the nonlinear testing phase. In the Load Cases SW5-SW6, the accelerations recorded three accelerometers (AC1-AC3) in the model lower part which increase linearly along the model height, but the acceleration recorded AC4 on the crest of the model decreases suddenly. This indicates cracks in the necks of the model under Load Cases SW5 and SW6. The accelerations recorded by the AC3 and AC4 in the model upper part are changed suddenly during Load Cases SW7 and SW8, and there is no law to follow for this change. It means that there are thorough cracks in the model upper part.

6.3. Cracking Responses and Failure Mode. For the dam model, 2 cracks started at the downstream surface of model and are located between 25 and $45 \mathrm{~cm}$ from the crest, respectively. Although 2 cracks have started at the downstream surface, only one major crack for the model has extended upward to the upstream surface. It thus has been observed that even if there are many damaged zones along the upper part of the downstream and upstream sides, only a single dominant crack separates the crest part from the main body of dam. The cracking responses of model during the testing are presented in Table 8 . Under load cases in the testing, the final damage forms of the model are shown in Figure 14.

According to Table 8, there are no visible cracks in the model during earthquake with PGA of $0.3458 \mathrm{~g}$. The seismic

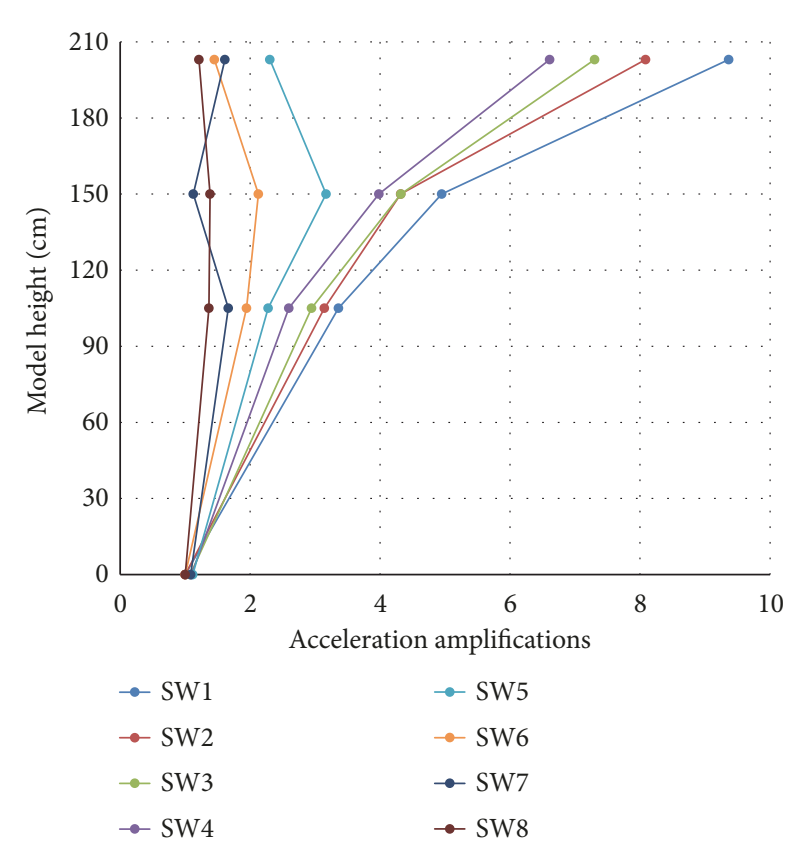

Figure 13: Acceleration magnifications along the model height under each load case.

characteristics of the prototype dam are got by adopting the scale ratios presented in Table 2. The design PGA of gravity dam is $0.251 \mathrm{~g}$; therefore the overload factor of dam is $1.378(0.3458 / 0.251)$ under the Chinese Code earthquake. It demonstrates that the dam is for safety in an intense earthquake.

6.4. Response of Strain. The strain is an important parameter to determine the damage of concrete-like material. The maximum tension strains and damage description for the model in the test are shown in Table 9. From Table 9, the larger values of maximum tension strains are obtained by FBG sensors No. 3, 4, 5, 6, 7, and 8. FBG sensors No. 3, 4, 5, 6, and 7 are arranged at the upstream and downstream sides of the model neck, is known that the dam neck is the damaged zone. For the model, the maximum strains of sensor No. 4 on the upstream surface and sensor No. 6 on the downstream surface are $1078 \mu \varepsilon$ and $1207 \mu \varepsilon$, respectively. This shows that the cracks in the positions of the dam will be completely opened in 
TABLE 8: Model crack responses during the testing.

\begin{tabular}{ll}
\hline Load case & Observations \\
\hline 1\#SW1 & No visible crack \\
1\#SW2 & No visible crack \\
1\#SW3 & No visible crack \\
1\#SW4 & No visible crack \\
1\#SW5 & The first crack appears at downstream surface of neck of model, the crack length is about $5 \mathrm{~cm}$. \\
1\#SW6 & The upstream surface of model is cracked, and the main crack at downstream extends to center of model section. \\
1\#SW7 & $\begin{array}{l}\text { At the downstream surface, the second small crack appears at } 20 \mathrm{~cm} \text { below the model crest, and the main crack expands } \\
\text { from moderate to severe cracks. }\end{array}$ \\
& $\begin{array}{l}\text { At the downstream surface, a crack appears at 70 } \mathrm{cm} \text { below the model crest (Dam waist), and the main crack runs through } \\
\text { the model, and a small crack appears above the second crack. Severe damage area is formed in the neck of the model, } \\
\text { shown in Figures 14(a), 14(c), and 14(d). }\end{array}$ \\
& shom
\end{tabular}
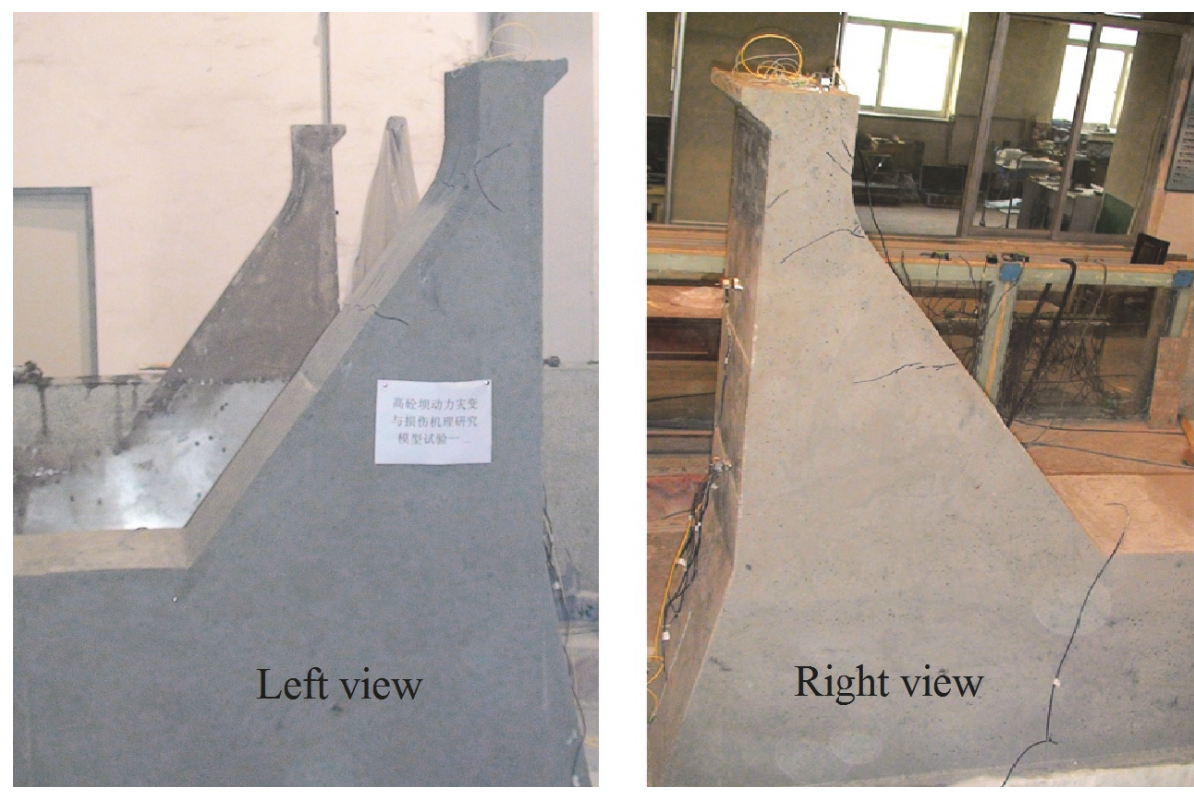

(a) Failure modes of the model

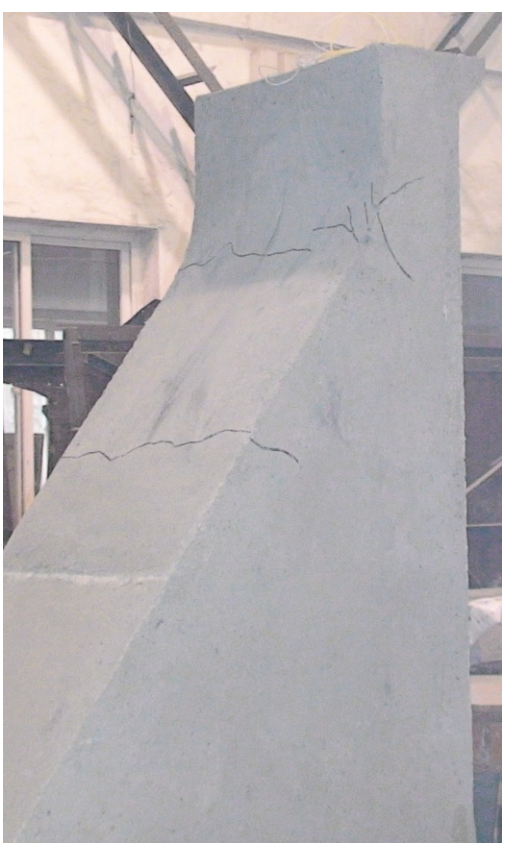

(b) Failure modes of the model from the facade

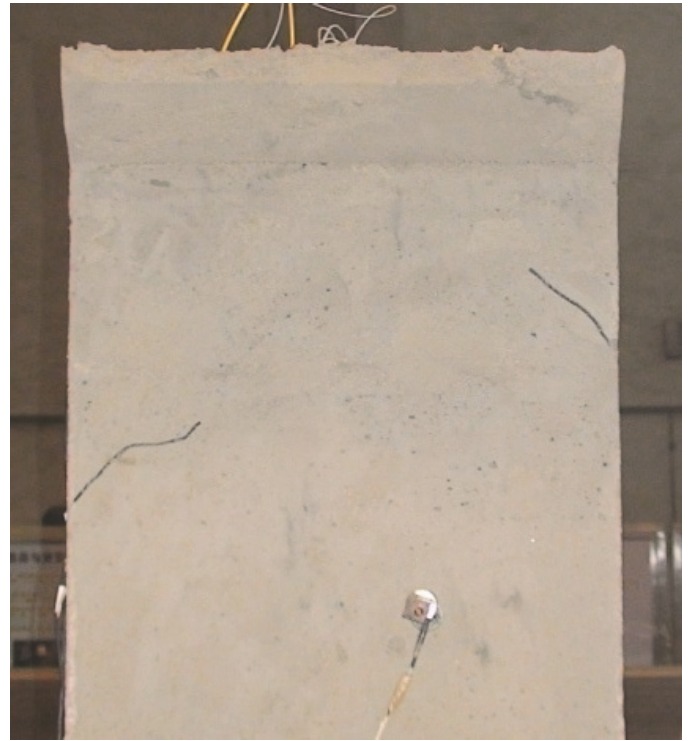

(c) Failure modes of the model on upstream surface

FIGURE 14: Illustration of the damaged zones of the model. 
TABLE 9: Max. tension strains and damage description for the model in the test.

\begin{tabular}{lcc}
\hline Strain gauge No. & Max. tensile strain/ $\mu \varepsilon$ & Damage description \\
\hline No. 1 & 102 & No visible crack \\
No. 2 & 64 & No visible crack \\
No. 3 & 396 & Visible small crack \\
No. 4 & 1078 & Severe crack \\
No. 5 & 484 & Moderate crack \\
No. 6 & 1207 & Severe crack \\
No. 7 & 241 & No visible crack \\
No. 8 & 594 & Moderate crack \\
No. 9 & 71 & No visible crack \\
No. 10 & 54 & No visible crack \\
\hline
\end{tabular}

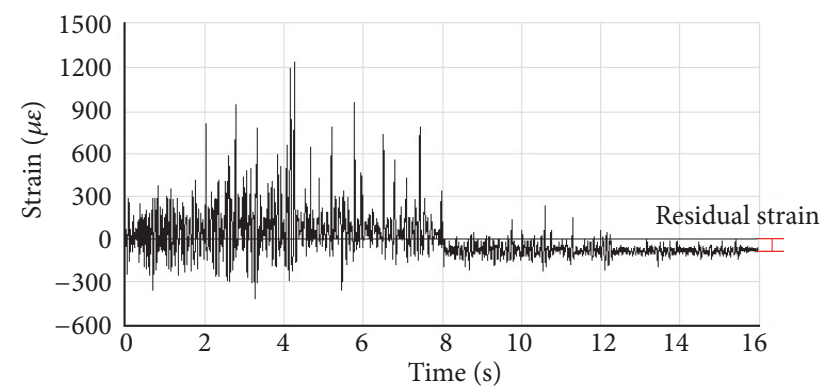

FIGURE 15: Strain time history of sensor No. 6 for the model during Load Case SW8.

the intense earthquake. According to the maximum strain of sensor No. 8 for model, the moderate crack is found in the position of waist of the model. The maximum tension strain of sensor No. 1 for the model exceeds the tension strain threshold of the SMM, but the no visible crack is observed in the locations of model (dam heel).

The strain time history curve of sensor No. 6 for the model during Load Case SW8 is shown in Figure 15. It can be seen that the residual strain of sensor No. 6 for the model is about $110 \mu \varepsilon$ at the end of the testing. This means that the model has completely irreversible damage.

\section{Conclusions}

In order to investigate the dynamic characteristics, seismic responses, failure mode, and safety evaluation of a $203 \mathrm{~m}$ high gravity dam under intense earthquake, a series of complete dynamic failure model tests on a shaking table are performed based on application of FBG strain sensor. At the end of the experimental study, the conclusions are as follows:

(1) The encapsulated FBG sensor proposed in the testing is used to measure strain. It obtains accurate strain data and overcomes the shortcomings of traditional strain gauge.

(2) A Simulation Model Material (SMM) presented in the paper can satisfy the similitude law requirements with the normal concrete. The SMM is easy to make, and the use of the model material making the dam models can complete the test well.

(3) According to the responses to the foundational frequency and acceleration during the testing, the dam is damaged under the Chinese Code seismic wave with PGA of $0.3458 \mathrm{~g}$. The same conclusion is got based on the damage process and strain response of the dam model during testing.

(4) The PGA producing the first crack in the concrete dam can be seen as an important parameter to estimate the safety of the dam in intense earthquake. The PGA for the first crack of the model during the testing is $0.3458 \mathrm{~g}$ and is almost 1.378 times of the design PGA. The PGA of the model completely failed is $1.4176 \mathrm{~g}$ and reflects 5.65 times the overload capacity of dam.

(5) The $203 \mathrm{~m}$ high concrete gravity dam can be made safe during an intense earthquake in its site area. But we should be aware that an earthquake of PGA beyond $0.4826 \mathrm{~g}$ may be catastrophic for the dam. So far the dam is designed to resist against an earthquake with a peak ground acceleration (PGA) under $0.251 \mathrm{~g}$.

\section{Data Availability}

The data used to support the findings of this study are available from the first or corresponding authors by wang.ming .ming@163.com or 443193288@qq.com upon request.

\section{Conflicts of Interest}

The authors declare that there are no conflicts of interest regarding the publication of this paper.

\section{Acknowledgments}

The authors are grateful to the reviewers for their very useful comments and suggestions. The study is fully supported by National Natural Science Foundation of China through Grant No. 51669008, Yunnan Talent Training Fund of China through Grant No. KKSY201404026, and Open Foundation of State Key Laboratory of coastal and offshore Sciences in Dalian University of Technology of China through Grant No. LP1619. 


\section{References}

[1] P. Leger and S. S. Bhattacharjee, "Seismic fracture analysis of concrete gravity dams," Canadian Journal of Civil Engineering, vol. 22, no. 1, pp. 196-201, 1995.

[2] Q. Cai, Finite element modeling of cracking in concrete gravity dams, Ph. D. thesis, Department of Civil Engineering, University of Pretoria, South Africa, 2007.

[3] Q. Cai, J. M. Robberts, and B. W. J. Van Rensburg, "Cracking in concrete using smeared cracking finite element modelling," South African Journal of Science, vol. 102, no. 11-12, pp. 548-556, 2006.

[4] Q. Cai, J. M. Robberts, and B. W. J. Van Rensburg, "Finite element fracture modelling of concrete gravity dams," Journal of the South African Institution of Civil Engineering, vol. 50, no. 1, pp. 13-24, 2008.

[5] L. Gao and H. Zhiqiang, "Earthquake safety assessment of concrete arch and gravity dams," Earthquake Engineering and Engineering Vibration, vol. 4, no. 2, pp. 251-264, 2005.

[6] M. Shi, H. Zhong, E. T. Ooi, C. Zhang, and C. Song, "Modelling of crack propagation of gravity dams by scaled boundary polygons and cohesive crack model," International Journal of Fracture, vol. 183, no. 1, pp. 29-48, 2013.

[7] T. Sasaki, K. Kanenawa, Y. Yamaguchi et al., "Seismic performance evaluation of concrete gravity dams," in Proceedings of the 13th World Conference on Earthquake Engineering, p. 1068, Vancouver, B.C., Canada, 2004.

[8] C. Zhang and F. Jin, "Seismic safety evaluation of high concrete dams Part I: State of the art design and research," in Proceedings of the 14th World Conference on Earthquake Engineering, Beijing, China, 2008.

[9] C. Jia, Y. Li, and Q. Ren, "Cracking analysis of high concrete gravity dams under floodwater and seismic effects," in Proceedings of the 2010 Asia-Pacific Power and Energy Engineering Conference, pp. 1-4, Chengdu, China, March 2010.

[10] A. Niwa and R. W. Clough, "Shaking table research on concrete dam models," Technical Report No. UCB/EERC-80/05, Earthquake Engineering Research Center, Berkeley, Calif, USA, 1980.

[11] J. Zhou and G. Lin, "Seismic fracture analysis and model testing of concrete gravity dams," Dam Engineering, vol. 3, no. 1, pp. 3548, 1992.

[12] J. Zhou, G. Lin, T. Zhu, A. D. Jefferson, and F. W. Williams, "Experimental investigations into seismic failure of high arch dams," Journal of Structural Engineering, vol. 126, no. 8, pp. 926935, 2000.

[13] T. Zhu, Research on similitude problems of structural dynamic models and technology of structural dynamic tests, Ph. D. thesis, Disaster Mitigation and Reduction Engineering, Dalian University of Technology, 2004.

[14] R. Bogdan, "Physical model method for seismic study of concrete dams," Bulletin of the Polytechnic Institute of Jassy Constructions Architechture, vol. 3, pp. 57-76, 2008.

[15] S. Fan, Research on dynamic failure tests and reliability of concrete gravity dam, Structural Engineering, Dalian University of Technology, 2007.

[16] B. Phansri, S. Charoenwongmit, P. Warnitchai, D. Shin, and K. Park, "Numerical simulation of shaking table test on concrete gravity dam using plastic damage model," Structural Engineering and Mechanics, vol. 36, no. 4, pp. 481-497, 2010.

[17] H.-H. Zhu, J.-H. Yin, J.-H. Dong, and L. Zhang, "Physical modelling of sliding failure of concrete gravity dam under overloading condition," Geomechanics and Engineering, vol. 2, no. 2, pp. 89-106, 2010.

[18] J. Chen, M. Wang, and S. Fan, "Experimental investigation of small-scaled model for powerhouse dam section on shaking table," Structural Control and Health Monitoring, vol. 20, no. 5, pp. 740-752, 2013.

[19] M. Wang, J. Chen, S. Fan, and S. Lv, "Experimental study on high gravity dam strengthened with reinforcement for seismic resistance on shaking table," Structural Engineering and Mechanics, vol. 51, no. 4, pp. 663-683, 2014.

[20] L. Lu, X. Kong, Y. Dong, D. Zou, and Y. Zhou, "Similarity relationship for brittle failure dynamic model experiment and its application to a concrete dam subjected to explosive load," International Journal of Geomechanics, vol. 17, no. 8, p. 04017027, 2017.

[21] S. S. Wang and Q. W. Ren, "Dynamic response of gravity dam model with crack and damage detection," Science China Technological Sciences, vol. 54, no. 3, pp. 541-546, 2011.

[22] M.-W. Seo, I. S. Ha, Y.-S. Kim, and S. M. Olson, "Behavior of concrete-faced rockfill dams during initial impoundment," Journal of Geotechnical and Geoenvironmental Engineering, vol. 135, no. 8, pp. 1070-1081, 2009.

[23] A. D. Kersey, M. A. Davis, H. J. Patrick et al., "Fiber grating sensors," Journal of Lightwave Technology, vol. 15, no. 8, pp. 1442-1463, 1997.

[24] H. N. Li, D. S. Li, and G. B. Song, "Recent applications of fiber optic sensors to health monitoring in civil engineering," Engineering Structures, vol. 26, no. 11, pp. 1647-1657, 2004.

[25] P. Biswas, S. Bandyopadhyay, K. Kesavan et al., "Investigation on packages of fiber Bragg grating for use as embeddable strain sensor in concrete structure," Sensors and Actuators A: Physical, vol. 157, no. 1, pp. 77-83, 2010.

[26] P. K. Chan, W. Jin, A. K. Lau, L. Zhou, D. Jiang, and A. Wang, "Strain monitoring of composite-boned concrete specimen measurements by use of FMCW multiplexed fiber Bragg grating sensor array," in Proceedings of the International Conference on Sensors and Control Techniques (ICSC2000), pp. 56-59, Wuhan, China, 2000.

[27] H. Naruse, Y. Uchiyama, T. Kurashima, and S. Unno, "River levee change detection using distributed fiber optic strain sensor," IEICE Transactions on Electronics, no. 3, pp. 462-467, 2000.

[28] M. Wang, J. Chen, H. Wei, and B. Song, "Experimental investigation of a small-scaled model for overflow section of a high gravity dam on shaking table," Advances in Mechanical Engineering, vol. 11, no. 2, Article ID 168781401982995, 2019.

[29] D. C. Betz, G. Thursby, B. Culshaw, and W. J. Staszewski, "Advanced layout of a fiber Bragg grating strain gauge rosette," Journal of Lightwave Technology, vol. 24, no. 2, pp. 1019-1026, 2006.

[30] L. Ren, H.-N. Li, J. Zhou, L. Sun, and D.-S. Li, "Application of tube-packaged FBG strain sensor in vibration experiment of submarine pipeline model," China Ocean Engineering, vol. 20, no. 1, pp. 155-164, 2006.

[31] P. A. Calderón and B. Glisic, "Influence of mechanical and geometrical properties of embedded long-gauge strain sensors on the accuracy of strain measurement," Measurement Science and Technology, vol. 23, no. 6, p. 065604, 2012.

[32] L. Jun, Y. Zhang, and W. Xu, "Research on enhancement sensitivity of embedded fiber Bragg grating sensor," Optik International Journal for Light and Electron Optics, vol. 125, no. 24, pp. 7211-7214, 2014. 
[33] K. Kesavan, K. Ravisankar, R. Senthil, B. Arun Sundaram, and S. Parivallal, "Studies on apparent strain using FBG strain sensors for different structural materials," Experimental Techniques, vol. 38, no. 5, pp. 31-38, 2014.

[34] S. Fan, L. Ren, and J. Chen, "Investigation of fiber Bragg grating strain sensor in dynamic tests of small-scale dam model," Structural Control and Health Monitoring, vol. 22, no. 10, pp. 1282-1293, 2015.

[35] P. Moyo, J. M. W. Brownjohn, R. Suresh, and S. C. Tjin, "Development of fiber Bragg grating sensors for monitoring civil infrastructure," Engineering Structures, vol. 27, no. 12, pp. 1828-1834, 2005.

[36] L. Ren, J. Chen, H.-N. Li, G. Song, and X. Ji, "Design and application of a fiber Bragg grating strain sensor with enhanced sensitivity in the small-scale dam model," Smart Materials and Structures, vol. 18, no. 3, Article ID 035015, 2009. 


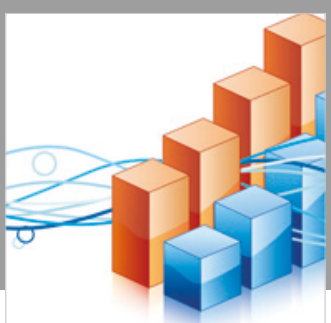

Advances in

Operations Research

\section{-n-m}
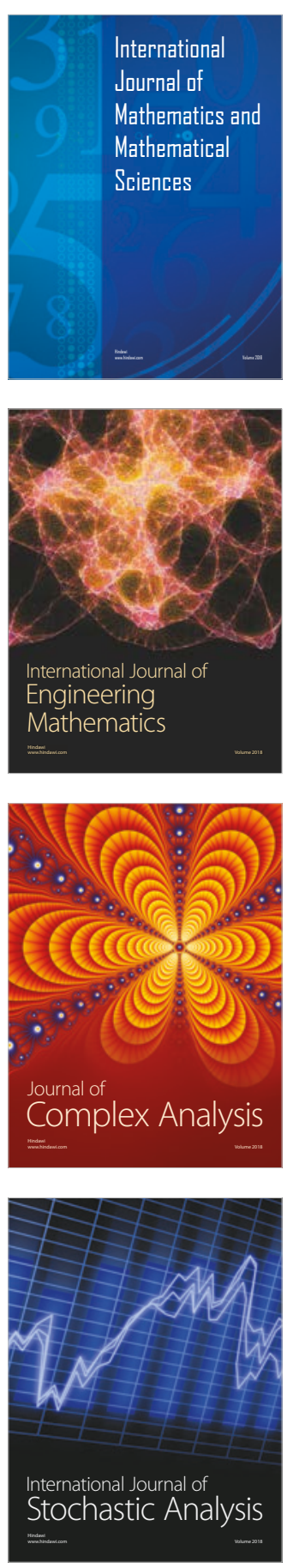
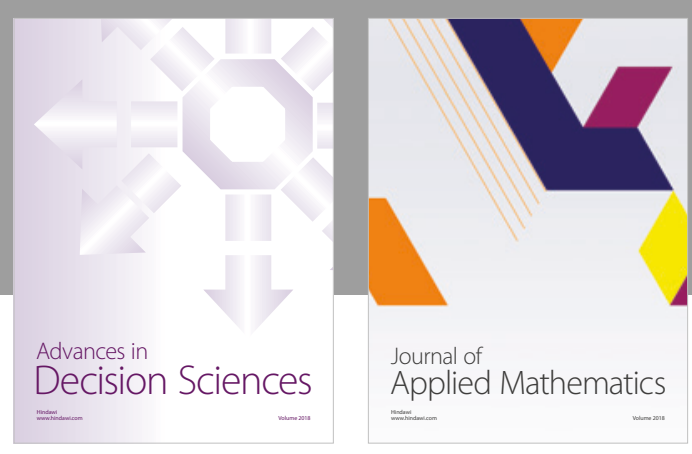

Journal of

Applied Mathematics
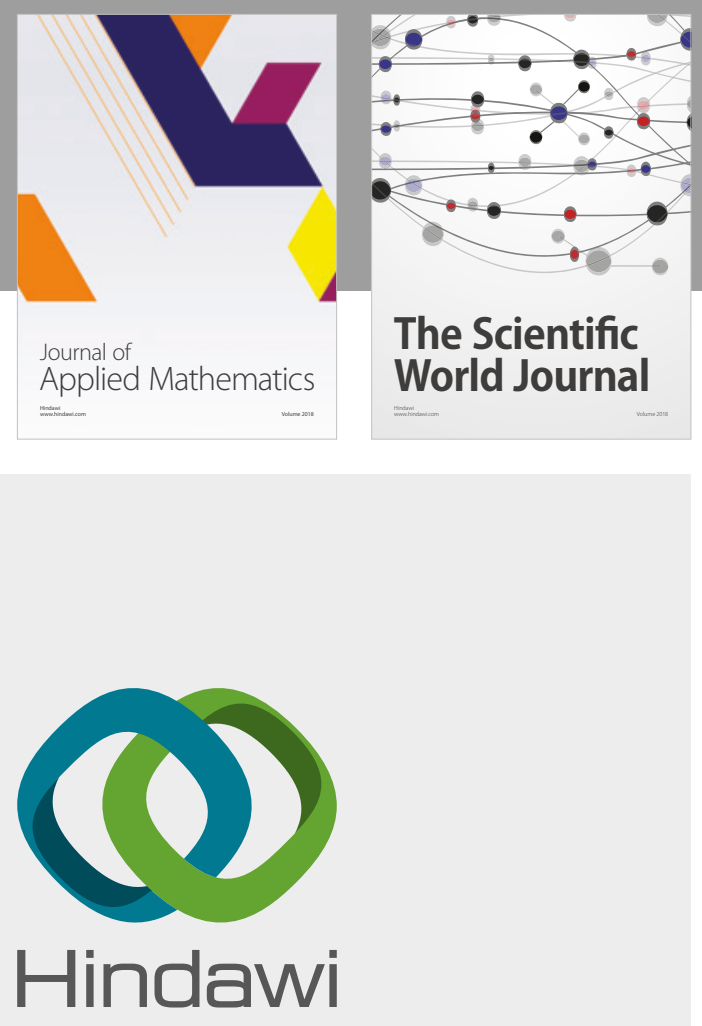

Submit your manuscripts at

www.hindawi.com

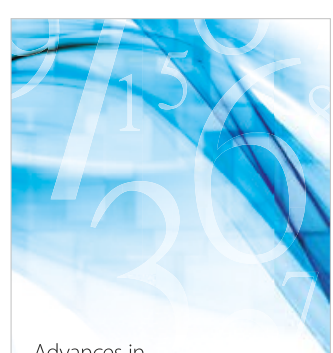

Advances in
Numerical Analysis
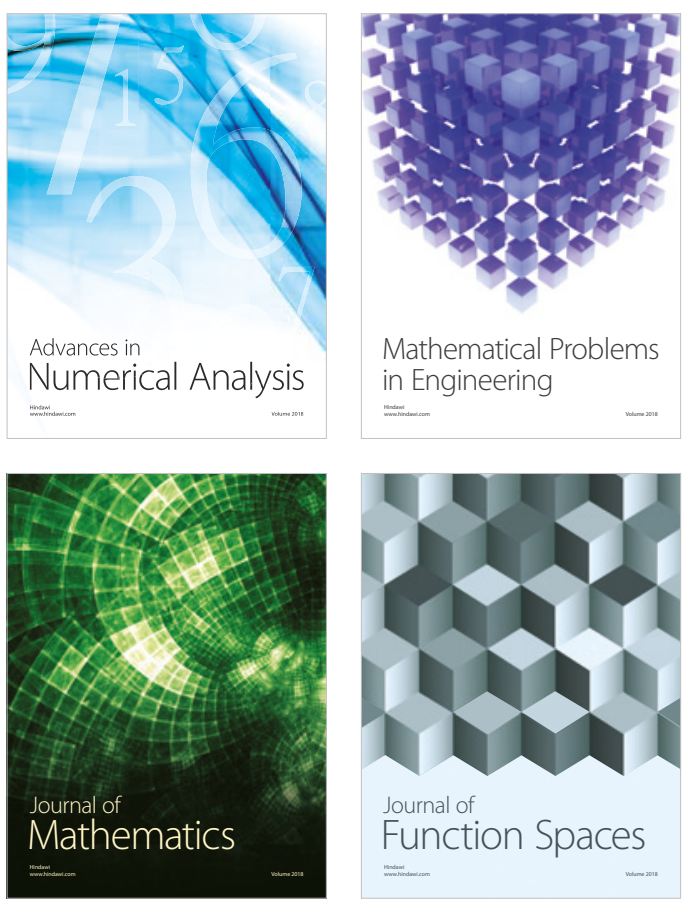

Mathematical Problems in Engineering

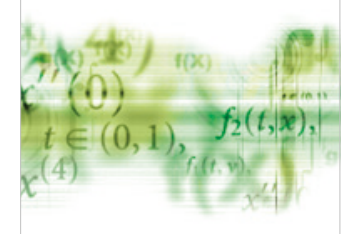

International Journal of

Differential Equations

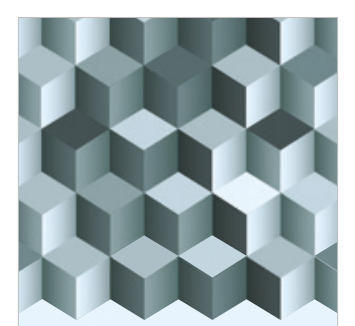

Journal of

Function Spaces
The Scientific

World Journal

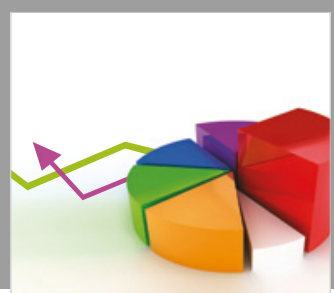

Journal of

Probability and Statistics
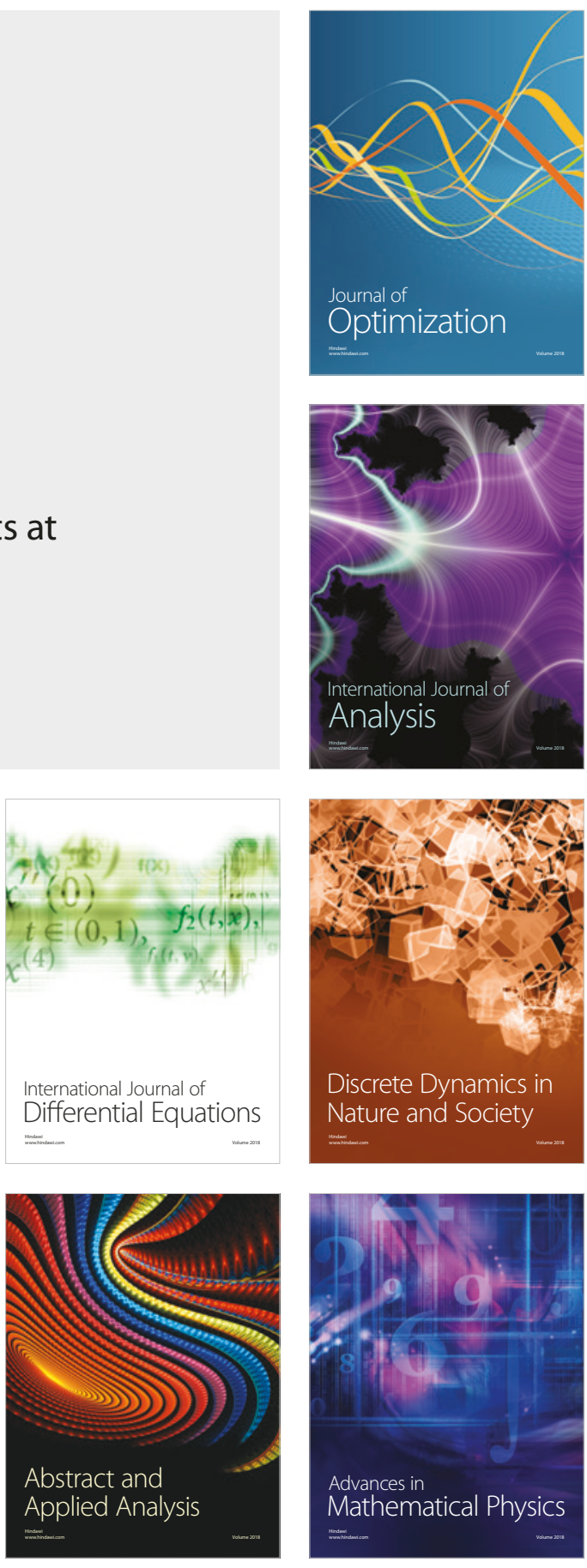